\title{
A formação do professor de ciências para os anos iniciais do Ensino Fundamental e a compreensão de saberes científicos
}

The formation of teacher of sciences for the early years of elementary school and understanding of knowledge scientific

Raquel Sanzovo Pires de Campos $^{1}$ Luciana Maria Lunardi Campos ${ }^{2}$

\section{Resumo}

Ressaltamos neste trabalho a importância dos alunos já nos primeiros anos do Ensino Fundamental comecem a caminhar em busca do desenvolvimento de saberes científicos, possuindo certo grau de domínio, de habilidades e recursos tornando-os capazes de confrontar determinadas situações. Considerando o papel de mediador do professor que lecionará Ciências nos primeiros anos do Ensino Fundamental, há de se considerar a sua formação inicial para o desenvolvimento da compreensão do que é um indivíduo cientificamente competente uma vez que os saberes científicos não são desenvolvidos espontaneamente entre os alunos. A proposta deste estudo foi, consequentemente, investigar a noção de saberes científicos em discentes do curso de licenciatura em Pedagogia. Identificada parcialmente em apenas um quarto dos discentes investigados, destacamos a importância da construção da noção dos saberes científicos como objetivo para esta etapa da educação básica.

Palavras chave: Formação Inicial; Saberes Científicos; Ensino de Ciências nos anos inicias do Ensino Fundamental; Pedagogia.

\section{Abstract}

We emphasize in this research project the importance that students already in the first years of elementary school begin to develop a scientific attitude, possessing some degree of mastery of skills and resources making them capable of facing certain situations. Considering the mediator role of the pedagogue teacher, who will teach Science in the early years of elementary school, we must consider, therefore, the initial formation in the understanding development of what it is a scientifically competent individual, because the scientific competent is not developed spontaneously among students. Therefore, this study investigated the development of comprehension of what is a scientific knowledge in Pedagogy students in Initial formation. Partially identified in only a quarter of Pedagogy students surveyed, we highlight the importance of the scientific knowledge notion construction as a goal for this basic education stage.

\footnotetext{
${ }^{1}$ raquelsanzovo@gmail.com

2 camposml@ibb.unesp.br
} 
Keywords: Initial Training; Scientific Knowledge; Science Education in the early grades of elementary school; Pedagogy.

\section{Introdução}

\section{A necessidade do desenvolvimento de saberes científicos}

No final da década de 1980, Fracalanza, Amaral e Gouveia (1987, p. 66-69) indicaram que o ensino de Ciências nos anos iniciais do Ensino Fundamental deveria considerar como função a aprendizagem dos conteúdos específicos e o desenvolvimento das habilidades de registro e de comunicação, desenvolvimento de habilidades manuais, o desenvolvimento de atitudes e interesses vinculados aos aspectos afetivos do ensino. Esses autores indicaram que nesta etapa as crianças estão propensas a admitir que os fenômenos científicos e naturais resultam de alguma finalidade humana e o pensamento infantil está profundamente ligado à experiência pessoal e ao envolvimento direto da criança com o assunto e, avançar além desses limites, significa ultrapassar a sua própria possibilidade biológica. Tal situação só se alteraria entre os oito e os dez anos, quando "novas condições biológicas aliadas ao enriquecimento das experiências pessoais da criança tornam possível partir-se do vivido e chegar-se ao domínio do espaço e tempo percebido".

Para os autores (FRACALANZA; AMARAL; GOUVEIA, 1987), as propostas usuais de atividades no ensino de Ciências estavam relacionadas a permitir o contato direito do aluno com os diversos aspectos ou recursos do seu ambiente; às atividades de experimentação (estudo sistemático em situações controladas); às atividades que envolviam comunicação (divulgação dos resultados de seus estudos sistemáticos), simulação e modelos (vivência do comportamento de um sistema, usando materiais e procedimentos que procuram representar, de modo simplificado, o próprio sistema).

Posteriormente, os Parâmetros Curriculares Nacionais (PNC's) indicam que o papel do ensino de Ciências no Ensino Fundamental é colaborar para a compreensão do mundo e suas transformações, situando o homem como indivíduo participativo e parte integrante do Universo, visando o desenvolvimento de "competências que lhe permitam compreender o mundo e atuar como indivíduo e como cidadão, utilizando conhecimentos de natureza científica e tecnológica" (BRASIL, 1997, p. 33).

Para tal documento (BRASIL, 1997), as atividades e os projetos de Ciências Naturais devem ser organizadas para que os alunos ganhem progressivamente as capacidades de observar, registrar e identificar características; comunicar semelhanças e diferenças; estabelecer relações; reconhecer processos e etapas; realizar experimentos simples; utilizar características e propriedades de materiais, objetos, seres vivos para elaborar classificações; e ainda:

formular perguntas e suposições sobre o assunto em estudo; organizar e registrar informações por meio de desenhos, quadros, esquemas, listas e pequenos textos, sob orientação do professor; comunicar de modo oral, escrito e por meio de desenhos, perguntas, suposições, dados e conclusões, respeitando as diferentes opiniões e utilizando as informações obtidas para justificar suas ideias; valorizar atitudes e comportamentos favoráveis à saúde, em relação à alimentação e à higiene pessoal, 
desenvolvendo a responsabilidade no cuidado com o próprio corpo e com os espaços que habita (BRASIL, 1997, p. 46-47).

Portanto, em síntese, podemos afirmar que Parâmetros Curriculares Nacionais de Ciências Naturais já traziam, no final da década de 90, a perspectiva de que são procedimentos fundamentais aqueles que permitem a investigação, a comunicação e o debate de fatos e ideias (BRASIL, 1997).

Concordando com tal afirmação, as pesquisas em ensino de Ciências posteriores indicavam que crianças de seis anos já podem acompanhar aulas baseadas em experimentação e observação. Ideias estas que foram colocadas em prática tanto nos Estados Unidos da América, por meio de currículos denominados "Ensino de Ciências Baseado em Investigação" e pelo projeto "Hands-on"; quanto na França, por meio do "La Main à la Pâte", programa direcionado aos alunos entre 5 e 12 anos de idade que tinha como objetivo primordial mostrar à criança que o saber não chega a ela como por mágica, mas, sim, porque foi conquistado.

Tais iniciativas ecoaram no Brasil e, em 2001, houve a implantação do programa "ABC na Educação Científica - Mão na Massa", da Faculdade de Educação da Universidade de São Paulo (HAMBURGUER, 2007; ZANON; FREITAS, 2007), sob proposta investigativa e reforço da importância da linguagem nas práticas educativas de ensino em Ciências Naturais.

Sabe-se que é inadequado exigir que os alunos dos anos iniciais percorram todo o ciclo investigativo, formulando claramente hipóteses e propostas de experimentos (ZANON; FREITAS, 2007). No entanto, iniciar este caminho, assumindo uma conduta de investigaçãoação na escolaridade inicial é possível e até necessário (ABEEG; BASTOS, 2005). Isto porque, ao chegarem ao primeiro ano do Ensino Fundamental os alunos já apresentam grande repertório de representações e explicação da realidade, tais como o reconhecimento do próprio corpo, percepção do tempo e do espaço (BRASIL, 1997).

À luz destas considerações torna-se visível o fato de que o processo de aprendizagem dos conhecimentos científicos envolvidos no ensino de Ciências Naturais é bastante complexo e envolve múltiplas dimensões, devendo possibilitar o desencadeamento de distintas ações cognitivas, tais como: manipulação de materiais, questionamento, observação, expressão e comunicação, verificação das hipóteses levantadas (ZANON; FREITAS, 2007).

Sob os diferentes pontos de vistas apresentados, parece não haver dúvidas que o ensino de Ciências envolve mais do que aprendizagem de conteúdos específicos, pois compreende também a aquisição de outros saberes científicos: saberes relacionados com as formas de compreender a ciência que ultrapassam a mera reprodução de conteúdos de ordem conceituais.

Embora com algumas especificidades, tais saberes por ora também são denominadas por outros autores de "competências científicas", "aprendizagens procedimentais", "procedimentos de investigação", "capacidades", "habilidades" ou, simplesmente, "modos de conhecer" (FURMAN, 2009).

Sob o ponto de vista do PISA, programa de avaliação internacional da OCDE (Organização para a Cooperação e Desenvolvimento Econômico), por exemplo, a competência científica se define como a capacidade de utilizar o conhecimento e os processos científicos, não só para compreender o mundo natural, mas também para intervir na tomada de decisões que o afetam (OCDE, 2006). Consequentemente, o indivíduo 
cientificamente competente é alguém que desenvolveu ações de captar, pensar, explorar; atender, perceber; formular; manipular e introduzir mudanças que permitem realizar uma interação competente em um determinado ambiente (QUINTANILLA, 2006).

Para além destas definições, estamos defendendo neste trabalho a ideia da formação científica que envolve a apropriação de conhecimentos, procedimentos e atitudes que possibilitam que cada indivíduo singular se aproprie da humanidade produzida histórica e coletivamente, podendo atuar e, acima de tudo, MODIFICAR a sociedade posta (SAVIANI, 2005).

Durante a prática pedagógica, para Gasparin (2009), é preciso que sejam privilegiados a contradição, a dúvida, o questionamento; valorizadas a diversidade e a divergência e interrogadas as certezas e as incertezas, despojando os conteúdos da sua forma naturalizada, pronta e imutável. Os conteúdos reúnem dimensões conceituais, científicas, históricas, econômicas, ideológicas, políticas, culturais, educacionais que devem ser explicitadas e apreendidas no processo de ensino-aprendizagem.

É importante ressaltar que estes saberes, atitudes ou competências não desenvolvidas espontaneamente e, portanto, todas estes saberes científicos precisam ser ensinados deliberadamente e, para aprendê-los alguém tem que ensiná-los, destinando tempo e estratégias específicas (FURMAN, 2009).

Dentro desta compreensão o ensino de Ciências nos anos iniciais se daria como 'experiência compartilhada', no qual o professor auxilia no caminho científico, auxilia no registro e na sistematização da experiência vivida e, nessa perspectiva, segundo Lima e Maués (2006), o papel do professor que ensina Ciências Naturais neste nível de ensino é "o de forçar a ascendência dos conceitos cotidianos, de mediar o processo que vai abrindo caminho para a posse dos conceitos científicos" (LIMA; MAUÉS, 2006, p. 169).

No processo de mediação entre o aluno e o objeto do conhecimento, o professor atua, intencionalmente, como agente cultural externo, possibilitando aos alunos o contato com a realidade científica. Como mediador, o trabalho do professor consiste em ações intencionais que conduzem os alunos à reflexão sobre os conceitos que estão sendo propostos (GASPARIN, 2005, p. 116).

Ao propor situações concretas como problemas, o professor cria um ambiente desafiador, que respostas tanto no âmbito intelectual quanto no âmbito da ação, desestabilizando conhecimentos existentes e criando situações para a apropriação de novos conhecimentos. Em que se estabeleçam os conflitos necessários para o ensinoaprendizagem.

Para isto, o professor deve estar preparado para instrumentar os alunos com o conhecimento científico historicamente acumulado, contextualizado nas questões sociais, econômicas, políticas e culturais de nossa sociedade e de nosso tempo (GERALDO, 2009).

A questão chave, no entanto, está em considerar que o professor de ciências dos anos iniciais "muitas vezes, têm a incumbência de ensinar conteúdos que não fizeram parte de sua formação acadêmica universitária, como Ciências" (BENETTI, 2011, p. 3).

Isto remete à questão da insegurança do educador generalista (BIZZO, 2012; ROCHA; MEGID NETO, 2009) que, pela carência destes conteúdos em sua formação, acaba recorrendo ao livro didático e a textos retirados da internet reduz à docência de Ciências Naturais à mera exposição de conceitos (BENETTI, 2011).

Ressaltamos aqui a importância da formação inicial no curso de Pedagogia em promover esta discussão sobre as práticas presentes em nosso cotidiano, seus pressupostos, 
suas demandas e suas possíveis críticas tornando-se claro o papel do professor generalista numa aula de ciências e seus objetivos perseguidos (BIZZO, 2012).

As preocupações com a melhor qualificação da formação de professores e com suas condições de exercício profissional não são recentes, mas são centrais, considerando-se a criticidade da situação, devido às omissões que se acumularam e foram progressivamente se agravando ao longo da história e os muitos desafios a superar (GATTI, 2009).

Dado o referido cenário e o crescente número de cursos superiores de licenciatura, destacamos neste trabalho a necessidade de fortalecimento da identidade dos cursos de formação de professores dos anos iniciais do Ensino Fundamental e da formação teórica dos pedagogos, pela compreensão de que os diversos problemas educacionais perpassam, direta ou indiretamente, a formação do professor.

Em relação à formação de professores para abordagem de Ciências Naturais, os desafios envolvidos na formação do Pedagogo que atuará nos anos iniciais são complexos. Hamburguer (2007); Ducatti-Silva (2008); Gatti e Barreto (2009); Gatti (2010); Mendes e Toscano (2011) indicam que:

1. A formação específica que visa o ensino de Ciências Naturais corresponde, geralmente, a uma pequena parte da carga horária do curso e não garantem formação completa no ensino em questão.

2. Ausência ou inadequação dos espaços físicos como laboratórios e bibliotecas;

3. Falta de preparo de pessoas especializadas no assunto [Ciências nos anos iniciais] capaz de oferecer respaldo na elaboração dos planejamentos e treinamento dos docentes.

As inúmeras carências durante a formação inicial acabam acarretando, mais uma vez, no despreparo para ensinar ciências por parte do professor, que acaba se utilizando de assuntos cotidianos (higiene, alimentação, etc.) conduzindo uma aula de forma mecânica (MENDES; TOSCANO, 2011).

Consideramos ser a formação inicial um momento fundamental, uma vez que é por meio desse processo, que os futuros professores podem adquirir e entrar em contato com conhecimentos, saberes e disposições iniciais. Afinal, a formação do professor, embora processo contínuo (MIZUKAMI; et al. 2002), contém um momento formal inicial realizado por instituições e um grupo de professores especializados, por intermédio de um currículo que envolve os conhecimentos básicos necessários para o exercício de determinada profissão e se dá fundamentalmente em nível universitário (GARCIA, 1999).

No entanto, como verificou Campos (2012) não parece estar entre as intenções formativas explicitas levar o futuro professor dos anos iniciais à compreensão dos objetivos de Ciências para esta etapa de ensino, fazendo com que o reconhecimento do papel do professor de Ciências por parte dos alunos em formação seja secundarizado.

Além disso, para autora (CAMPOS, 2012) acima do reforço dos conteúdos científicos básicos, promover a aquisição de saberes relacionados ao desenvolvimento de saberes científicos em alunos dos anos iniciais do Ensino Fundamental, seria um melhor caminho.

Concordamos o fato de o professor que desenvolve conteúdos de Ciências, de um modo geral, terem necessidades formativas específicas para além de conhecer a matéria a ser ensinada, como discutido por Carvalho e Perez (2009). Afinal, cabe ao professor mediar a formação de seus alunos, proporcionando a socialização dos conhecimentos científicos, dos processos e procedimentos científicos para que os alunos possam não só compreender o mundo natural, mas também para intervir na tomada de decisões que o afetam. 
E de que modo esta compreensão pode ser desenvolvida no contexto da Formação Inicial do Pedagogo?

Considerando que o futuro professor de Ciências para os anos inicias deve dominar instrumentos teóricos que o possibilite pensar sobre a prática e refletir sobre suas ações, defendemos que sejam oferecidas condições para que futuros professores construam saberes científicos e sobre como desenvolvê-los entre seus alunos. Por conseguinte, nos perguntamos se há apropriação, durante a formação inicial, da noção de saberes científicos entre os discentes de um curso de licenciatura em Pedagogia, como exposto abaixo.

Descrição geral da pesquisa: a formação do professor de ciências para as anos iniciais do ensino fundamental

Face a estes questionamentos, este trabalho teve como objetivo investigar o desenvolvimento da noção de saberes científicos em discentes do curso de licenciatura em Pedagogia.

Os dados foram levantados por meio de questionário explorativo com 27 graduandos do último ano de um curso em Licenciatura em Pedagogia de uma universidade pública situada no interior do estado de São Paulo, com objetivo de buscar compreender histórias pessoais e experiências que apresentarem correlação com o ensino de Ciências, pormenores e detalhes particulares da temática analisada: a construção dos saberes científicos.

Os discentes participantes foram renomeados como D1 a D27 para proteção de suas identidades.

Para análise dos dados, optamos pela análise de conteúdo (AC) uma vez que ela nos permite reconstruir indicadores e cosmovisões, valores, atitudes, opiniões, preconceitos e estereótipos (BARDIN, 2009; BAUER, 2002), e, portanto, é de grande valia quando objetivamos compreender a apropriação da noção de saberes científicos no curso de Pedagogia para a atuação na área de Ciências Naturais nos primeiros anos do Ensino Fundamental.

Durante a análise, partimos da identificação de elementos particulares de referências (recursos, conteúdos, competências, etc.) para, então propor agrupamentos em diferentes categorias (BARDIN, 2009).

\section{Resultados}

\section{A formação do professor de ciências para as séries iniciais do ensino fundamental}

Os resultados obtidos foram organizados em dois agrupamentos, o primeiro reunindo respostas relacionadas ao papel do professor que ensina ciências naturais nos anos iniciais e o segundo, à compreensão da noção de saberes científicos pelos licenciandos.

Em relação ao papel do professor de ciências nos anos iniciais, foi possível identificar as seguintes categorias apresentadas abaixo:

1) Transmissão/ Construção de conteúdos conceituais: o papel do professor tem foco na Transmissão e Construção de Conteúdos conceituais específicos da área de 
ciências naturais e adaptados à faixa etária; apresentando, ou não exemplos, como apresentado abaixo:

"O professor de ciências deve transmitir conhecimentos relacionados aos conteúdos de ambiente, terra e universo, ser humano e saúde e recursos tecnológicos. Além de abordar outras temáticas que são impostas pelo PCN" (D9)

2) Intervenção e desenvolvimento: $O$ papel do professor de ciências naturais tem foco nos processos de mediação, intervenção, animação e promoção do desenvolvimento cognitivo do aluno por meio de seu envolvimento ativo com o conhecimento. Por exemplo:

"O papel do professor de ciências naturais nas séries iniciais é ser o mediador, afim de proporcionar ao aluno uma reflexão de ideias para que ele possa construir e reconstruir seu conhecimento". (D7)

3) Promoção de Saberes Científicos: além das construções de conteúdos específicos da área de ciências naturais, considerou um conjunto de conhecimentos, procedimentos, repertórios científicos para compreender, agir e intervir, bem como a necessidade de desenvolvimento de saberes científicos afim de uma compreensão mais ampla de ciência. Segue trecho representativo:

[...] "é o questionar e investigar os fenômenos diários voltados a explicações que mais se aproximam da realidade para assim sair um pouco do fantasioso para o aprendizado de conhecimentos teóricos sólido, isso pode ser feito através de investigações, debates e pesquisas, voltados ao tema estudado" (D5).

4) Definições genéricas: Grupo de respostas aparentemente sem correlação direta à temática buscada, tal como:

[...]Nos anos iniciais o professor deve mostrar as ciências que rodeia a criança. Pode mostrar à criança que o cotidiano dela está repleto de ciências naturais. (D23)

Tabela 1: Categorias de caracterização do papel do professor de ciências para os anos iniciais do Ensino Fundamental apontadas pelos discentes.

\begin{tabular}{ccc}
\hline $\begin{array}{c}\text { O papel do Professor que } \\
\text { ensina Ciências Naturais nos } \\
\text { anos iniciais }\end{array}$ & Total de Discentes & Discentes \\
\hline $\begin{array}{c}\text { Transmissão/Construção de } \\
\text { Conteúdos Conceituais }\end{array}$ & 10 & D8; D9; D11; D19; D21; D22; D24; \\
Intervenção e Desenvolvimento & 05 & D25; D26; D27 \\
Promoção de Saberes Científicos & 07 & D2; D3; D4; D7; D12 \\
Definições genéricas & 05 & D1; D13; D14; D18; D23 \\
\hline
\end{tabular}

Assim, ao categorizamos como os discentes caracterizam do papel do professor de ciências para os anos iniciais do Ensino Fundamental (Tabela 1) é possível indicar que dos 27 graduandos pesquisados, dez (10) descreveram ter o pedagogo o papel de "Transmissão/Construção de Conteúdos Conceituais"; 05 (cinco) o papel de "Intervenção e 
Desenvolvimento" e 07 (sete) o de "Promoção de Saberes Científicos". Não foi possível identificar o papel do pedagogo no ensino de ciências em 05 (cinco) definições genéricas.

Pelos dados obtidos, verificamos, também, como os licenciandos compreendem a noção de saberes científicos, organizando as respostas em três categorias:

1) Não compreensão dos Saberes Científicos: Compreende o ensino de ciências como sinônimo de transmissão e/ou construção de conteúdos específicos da área de ciências naturais esperados e/ou adaptados para a faixa etária. Não há necessidade de construção de saberes científicos, como no apresentado abaixo:

"[...]É transmitir conhecimento, saber passar de forma correta, aquilo que você "domina". Pode ser desenvolvida para os alunos de várias formas, tanto teoricamente ou prática para o aluno compreender melhor". (D27)

2) Compreensão dos Saberes Científicos: Necessidade, no ensino de ciências, de promover entre os alunos dos primeiros anos um conjunto de conhecimentos, procedimentos, repertórios científicos para compreender, agir e intervir, bem como a necessidade de desenvolvimento de saberes científicos afim de uma compreensão mais ampla de ciência. Exemplo:

"é o questionar e investigar os fenômenos diários voltados a explicações que mais se aproximam da realidade para assim sair um pouco do fantasioso para o aprendizado de conhecimentos teóricos sólido, isso pode ser feito através de investigações, debates e pesquisas, voltados ao tema estudado". (D5)

3) Definições genéricas: Respostas nas quais não foi possível perceber uma compreensão do que são os saberes científicos.

"São todas as informações que não mitos(senso comum). É importante desenvolve-la a partir de discussões e atividades programadas entorno de mitos e verdades absolutas construídas socialmente que não são verdadeiros e já foram desmistificados cientificamente" (D26)

Conforme exposto na Tabela 2, podemos observar que 07 discentes apresentaram a compreensão esperada do que são os saberes científicos.

Tabela 2: Categorização da compreensão da necessidade de construção de saberes científicos entre os discentes.

\begin{tabular}{ccc}
\hline & $\begin{array}{c}\text { Total } \\
\text { Discentes }\end{array}$ & Discentes \\
\hline $\begin{array}{c}\text { Não compreensão dos } \\
\text { Saberes Científicos } \\
\begin{array}{c}\text { Compreensão dos Saberes } \\
\text { Científicos }\end{array}\end{array}$ & 16 & D1; D2; D3; D4; D6; D8; D9; D11; D12; D14; D19; \\
Definições genéricas & 07 & D21; D22; D24; D25; D27 \\
\hline
\end{tabular}

De modo geral, foi possível identificar entre os 27 discentes analisados, o reconhecimento, por 14 indivíduos da necessidade de construção de saberes científicos entre seus futuros alunos. Logo, parece ter ocorrido apropriação, durante a formação inicial, da noção de saberes científicos entre pelo menos metade dos discentes do curso de licenciatura em Pedagogia. 
A opção por "saberes científicos", não se dá como a opção de nomenclatura uma vez que ensino de ciências vai muito mais além do conhecimento de conteúdos específicos, mas também vai muito além da mera aquisição de habilidades e/ou competências. Afinal, se o saber é social e decorre no interior das relações sociais, tão importante como saber adquirilos e saber como compreendê-los e os articularem à própria prática social.

O primeiro passo para isso, portanto, é nos afastar cada vez mais da imagem da Ciência como uma verdade absoluta, um pensamento superior que encontra-se quase como uma atividade não humana. Afinal,

a ciência resolve problemas mas é mais do que isso. Ela permite a indústria e a criação de riquezas, mas é mais do que isso. Ela é um modelo de conhecimento válido, uma expressão do estágio que alcançamos em nossa capacidade de relacionar dados e criar modelos que reflitam a dialética entre experimentação e teorização (SANTOS, 2005, p.42)

Cabe ao professor de ciências, já no Ensino Fundamental I, explicar os mecanismos que regem não somente a organização e o funcionamento do pensamento científico e da influência humana no meio ambiente, mas também quais suas decorrências, implicações e qual a sua função.

Este não é um processo de fácil elaboração.

Se a ciência é produzida por humanos, para humanos é realizada socialmente em um determinado momento histórico. Logo, não há decisões científicas tomadas ou a serem tomadas atemporalmente ou descobertas magnificentes que não passem pela sociedade humana, dentro da estrutura social hegemônica atual, a estrutura do capital.

Consequentemente, para promover entre os alunos a construção de saberes científicos é fundamental que o professor esteja preparado. Primeiro por meio dos conhecimentos didáticos, utilizando-se das diversas técnicas de ensino e dos princípios metodológicos (GERALDO, 2009) e suas respectivas análises críticas e segundo, pelo reconhecimento do seu próprio papel ideológico e político como mediador e, é claro, ter consciência dos objetivos que irão permear a sua ação docente.

Mesmo que os licenciandos aqui estudados oscilaram entre apontar o papel de transmissão/construção de conteúdos conceituais, mediação e de promoção dos saberes científicos destaca-se que os mesmos não são excludentes.

Seria de grande valia construir, entre os licenciandos a ideia que cabe ao professor mediar por meio da própria transmissão dos conteúdos, procedimentos e atitudes bem como a própria compreensão do que é ciência, como se faz a mesma, e o que é ensiná-la.

Para além dos agrupamentos encontrados, uma observação ainda se torna importante: a necessidade do vínculo com o cotidiano, do saber do dia a dia, esteve presente em 03 respostas observadas. Estas respostas não indicaram a necessidade de sua superação rumo à compreensão científica mais complexa e sintética.

Não excluindo a importância da contextualização dos conteúdos, destacamos a necessidade da superação do cotidiano, passando da percepção particular da realidade (da compreensão sincrética da vida cotidiana), para uma compreensão de totalidade do conhecimento científico.

Atuando intencionalmente como agente cultural externo, o professor deve possibilitar aos alunos o contato com a realidade científica ao aproximar o aluno do objeto do conhecimento, confrontando o conhecimento cotidiano e fazendo-os elevar-se aos 
científicos. Assim, dentro de uma perspectiva de cientificidade, faz com que os "conhecimentos cotidianos sejam transformados em científicos, a fim de que estes se tornem cotidianos", (GASPARIN, 2005, p.116).

\section{Considerações finais}

\section{O que podemos dizer sobre o desenvolvimento da compreensão de saberes científicos na formação inicial?}

Este trabalho buscou ressaltar necessidade do desenvolvimento de saberes científicos em alunos dos anos iniciais do ensino fundamental e, por conseguinte, desenvolver saberes relacionados a esses aspectos durante a formação inicial do professor que atuará nestes anos, o Pedagogo.

Afinal, embora compreendendo os fatores macro sociais envolvidos no processo de formação dos professores, entendemos que, no caso da aquisição de conhecimentos, competências e disposições para o ensino, a formação inicial é um momento estratégico.

Ressaltamos a importância de disciplinas relacionadas à Metodologia e Conteúdos de Ensino de Ciências no curso de Pedagogia no oferecimento de subsídios teóricos metodológicos, conceituais, e acima de tudo, na compreensão de que o ensino de Ciências apresenta métodos específicos (modalidades didáticas), recursos próprios (GERALDO, 2009; KRASILCHIK, 2000) e envolve a aquisição de saberes científicos, noção esta, que no curso analisado, esteve presente em apenas um quarto dos graduandos.

A formação inicial deve proporcionar a compreensão de que ciência é processo: "a mais desenvolvida forma em que se apresenta a racionalidade contemporânea". Pois, assim como a realidade social objetiva discutida, a ciência também é produto de ação dos homens. A ciência é histórica, determinada por crenças, tradições, ideologia de classes, interesses políticos e econômicos. Logo, sua própria estrutura também deve ser problematizada.

Rumo à construção de saberes científicos, o primeiro passo é desmantelar cada vez mais a imagem da Ciência como uma verdade absoluta, um pensamento superior que encontra-se quase como uma atividade não humana. E se a ciência é produzida por humanos, para humanos é realizada socialmente em um determinado momento histórico. Logo, não há decisões científicas tomadas ou a serem tomadas atemporalmente ou descobertas magnificentes que não passem pela sociedade humana, dentro da estrutura social hegemônica atual.

O ensino de ciências já anos inicias do Ensino Fundamental deve também considerar este processo, e o pedagogo necessita desenvolver esta compreensão na qual "os conteúdos científicos necessitam, hoje, ser reconstruídos em suas plurideterminações, dentro das novas condições de vida humana, respondendo, quer de forma teórica, quer de forma prática aos novos desafios propostos" (GASPARIN, 2009, p. 3).

Fica cada vez mais claro a importância de tornar claro o papel do pedagogo ao atuar no ensino de ciências e seus objetivos perseguidos, como indicou Bizzo (2012) e Campos (2012). Fazer com que o aluno adquira saberes científicos de modo a compreender o que é a ciência e o mundo, de modo que o mesmo possa agir e intervir historicamente nele, com certeza deve ser um deles. 


\section{Referências}

ABEEG, I.; F. P. BASTOS, 2005. Fundamentos para uma prática de ensino-investigativa em ciências naturais e suas tecnologias: exemplar de uma experiência em séries iniciais. Revista Electrónica de Enseñanza de las Ciencias. v. 4 n.3, 2005.

BARDIN, L. Análise do Conteúdo. Lisboa: Edições 70. 2009.

BAUER, M. W.; BENETTI, B. O ensino de Ciências nas séries iniciais do ensino fundamental: construindo diálogos em formação continuada. In.: Atas do VII Encontro Nacional de Pesquisa em Educação em Ciências (ENPEC). Campinas: ABRAPEC, 2011.

BENETTI, B. O ensino de Ciências nas séries iniciais do ensino fundamental: construindo diálogos em formação continuada. In: Atas do VII Encontro Nacional de Pesquisa em Educação em Ciências (ENPEC). Campinas: ABRAPEC, 2011.

BIZZO, N. M. V. Metodologia e prática de ensino de ciências: A aproximação do estudante de magistério das aulas de ciências no $1^{\circ}$ grau. Disponível em: <http://www.ufpa.br/eduquim/praticadeensino.htm>. Acesso em: jul. 2012.

BRASIL. Secretaria de Educação Fundamental. Parâmetros curriculares Nacionais: ciências naturais. Brasília: MEC/SEF, 1997.

CAMPOS, R.S.P.A. Prática do formador de professor de Ciências no curso de Pedagogia: intenções e ações. Trabalho de conclusão de curso. Bauru, 2012.

CARVALHO, A. M. P.; GIL-PÉREZ, D. Formação de professores de ciências: tendências e inovações. 9.ed. São Paulo: Cortez, 2009.

DUCATTI-SILVA, K. C. A Formação no curso de Pedagogia: Metodologia para o Ensino de Ciências. In: CAPELLINI, V. L. M; MANZONI, R. M. Políticas públicas, práticas pedagógicas e ensino-aprendizagem: diferentes olhares sobre o processo Educacional. São Paulo: Cultura Acadêmica, 2008.

FRACALANZA, H.; AMARAL, I. A.; GOUVEIA, M. S. F. O ensino de Ciências no Primeiro Grau. São Paulo: Atual, 1987. 124 p.

FURMAN, M. O ensino de Ciências no Ensino Fundamental: colocando as pedras fundacionais do pensamento científico. São Paulo: Instituto Sangari, 2009.

GARCÍA, C. M. Estrutura Conceptual da Formação de Professores. In: GARCÍA, C. M. Formação de professores: para uma mudança educativa. Tradução de Isabel Narciso. Porto - Portugal: Porto Editora, 1999.

GASPARIN, J. L.; Uma didática para a Pedagogia Histórico-Crítica. 5. ed. Campinas: Autores Associados 2009. 190 p.

GATTI, B. A. Licenciaturas: Crise Sem Mudança?. In: DALBEN, A. I. L. F [et al.]. [orgs] Convergências e tensões no campo da formação e do trabalho docente. Livro 4, Belo Horizonte: Autêntica, 2010.

GATTI, B. A; BARRETO, E. S. S. Professores do Brasil: impasses e desafios. - Brasília: UNESCO, 2009. 
GERALDO, A. C. H. Didática das Ciências Naturais na perspectiva histórico-crítica. Campinas, SP: Autores Associados, 2009. 170 p.

HAMBURGUER, E. W. Apontamentos sobre o ensino de Ciências nas séries escolares iniciais. Estudos Avançados, v. 21, n. 60, 2007.

KRASILCHIK, M. Reformas e realidade: o caso do ensino das ciências. São Paulo em Perspectiva, v. 14, n. 1, 2000, p. 85-93.

LIMA, M. E. C. C.; MAUÉS, E. Uma Releitura do Papel da Professora das Séries Iniciais no Desenvolvimento e Aprendizagem de Ciências das Crianças. Ensaio. v. 8, n. 2, dez. 2006.

MENDES, J. S. B.; TOSCANO, C. O ensino de ciências nos anos iniciais: um estudo com acadêmicas de pedagogia. In.: Atas do X Congresso Nacional de Educação - EDUCERE. Curitiba, nov. 2011.

MIZUKAMI, M. G. N., et al. Introdução e Cap. 1 - Formação de professores: concepção e problemática atual. In: MIZUKAMI, M. G. N (Org.). Escola e aprendizagem da docência: processos de investigação e formação. São Carlos : EdUFSCar, 2002. p. 7- 45.

OCDE. PISA 2006. Marco de la evaluación. Conocimientos y habilidades en Ciencias, Matemáticas y Lectura. Paris: OCDE. 2006.

ROCHA, M. B.; MEGID NETO, J. Práticas de Formação de Professores para o Ensino de Ciências nas Séries Iniciais do Ensino Fundamental. In.: Atas do Encontro Nacional de Pesquisa Em Educação em Ciências. (ENPEC), VIII, 2009. Florianópolis: ABRAPEC, 2011.

QUINTANILLA, M. 2006. Identificación, caracteización y evaluación de competencias científicas desde uma imagen naturalizada de la ciencia. In.: ADÚRIN-BRAVO, A.; QUINTANILLA, M. Enseñar ciencias en el nuevo milenio: retos y propuestas. Santiago: Ediciones Universidad Católica de Chile, 2006.

SANTOS, C. S. Ensino de ciências: abordagem histórico-crítica. Campinas-SP: Armazém do ipê, 2005.

SAVIANI, D. Pedagogia Histórico-Crítica: primeiras aproximações. 9. ed. Campinas: Autores associados, 2005.

ZANON, D. A. V.; FREITAS, D. A aula de ciências nas séries iniciais do ensino fundamental: ações que favorecem a sua aprendizagem. Ciências \& Cognição, v. 10, 2007. p. 93-103. 